\title{
Expanding primary care in South and East Asia
}

Chris van Weel and Ryuki Kassai look at efforts to strengthen primary care and call for regional and international collaboration to help implement policy

\author{
Chris van Weel emeritus professor of general practice ${ }^{12}$, Ryuki Kassai professor of family medicine ${ }^{3}$ \\ ${ }^{1}$ Department of Primary and Community Care, Radboud University Medical Center, Nijmegen, Netherlands; ${ }^{2}$ Department of Health Services Research \\ and Policy, Australian National University, Canberra, Australia; ${ }^{3}$ Department of Community and Family Medicine, Fukushima Medical University, \\ Fukushima, Japan
}

More than $60 \%$ of the world population live in Asia, with substantial numbers in very deprived socioeconomic conditions. The heterogeneity between the countries of the region is reflected in their health systems, which vary from well developed to virtually absent. Providing access to care, in particular for those at greatest need, is a regional priority ${ }^{1}$ that comes on top the more general global challenge of transforming health systems to respond better to the needs of ageing populations with chronic health problems and increasing health costs. ${ }^{2}$

Health systems based on primary care have been shown to achieve better equity and better population health at lower costs. ${ }^{3-5}$ Patients with chronic conditions in countries with strong primary healthcare are more likely to be in good or very good health than those in countries with less well developed primary care. ${ }^{6}$ The same is true for frail patients with multiple chronic conditions..$^{7-9}$ This evidence has led to a global strategy to strengthen primary care,$^{111}$ focusing on introducing comprehensive, continuity of care in a person and population centred approach $^{12}{ }^{13}$ under prevailing local conditions. ${ }^{14}$

Primary healthcare has to be built from the community where it has to operate, so knowledge of population needs and the existing health system is important in initiating reforms. However, most of the available experience and insight come from Europe and North America, ${ }^{15} 16$ with data for many other many countries and regions, including South and East Asia scarce. ${ }^{17}$ The World Organisation of Family Doctors (WONCA) therefore took the initiative to document how primary care is organised around the world and to create discussion about how the values of primary care can be adopted within the constraints of different healthcare systems. ${ }^{18}$ This article focuses on the findings from two recent workshops at WONCA conferences in the Asia Pacific (2015) ${ }^{19}$ and South Asia $(2016)^{20}$ regions, which critically appraised the health systems of Bangladesh, China (Shanghai region), Hong Kong, India, Japan, Nepal, Pakistan, Republic of Korea (South Korea), Singapore, Sri Lanka, and Taiwan.

\section{Health systems in South and East Asia}

The countries considered varied substantially in socioeconomic viability and in history and development of their health systems. But despite these differences, all countries were trying to strength primary healthcare. The main drivers of this policy were rising healthcare costs and the demographic changes of ageing populations with an increase of chronic health problems and multimorbidity.

In general, there is over-reliance on the hospital setting as the main provider of care and poor coordination between the hospital and community health services. This was true even in countries with developed primary care systems (Singapore, Shanghai-China, Hong Kong, and Sri Lanka). The teaching and training of health professionals - and in particular of physicians - takes place virtually exclusively in hospitals, with a strong focus on specialisation and a lack of recognition and understanding of the importance of generalist professional skills and competencies.

In most health systems the private sector, with direct out-of-pocket payment, played an important role.

\section{Implementation of primary care policy}

From the country descriptions and discussions, we determined four themes that are key to determining the outcome of primary care reforms: policy setting to plan a long term process of system change; leadership of primary healthcare professionals; finance and access; and multidisciplinary approach directed at health needs in the population.

\section{Policy setting}

Implementation of primary healthcare requires a policy to secure access to healthcare at the community level in conjunction with measures to guarantee that the policy is enacted. This means provision of community based healthcare facilities, the development of primary healthcare teams, and training professionals to deal with the prevailing health problems and 
needs in the community and the expectations that come with them.

Singapore and Shanghai-China exemplified this in their primary health policies, which are currently working to introduce a listing of patients with community practices and a primary healthcare gatekeeping function ${ }^{19}$ in combination with investment in community facilities, team development, and teaching and training. In other countries policy regulation is either absent, haphazard, or disconnected from strategic planning to implement these regulations in the community.

\section{Primary care leadership}

Professional leadership is required to translate policy into daily practice in the community. A critical mass of trained primary healthcare professionals is therefore essential, but achieving it is made difficult by the subordinate position of primary healthcare to hospital specialists and hospital care oriented medical schools. Furthermore, even though most countries provide training in primary care, non-specialised doctors and hospital specialists can continue to practise in the community, directly accessible by patients. This may support the reallocation of care from the hospital to the community, but primary care is more than that-it means the transformation of care focused on disease management to person or population centred care, including prevention and promotion of health.

\section{Finance and access}

In most of the countries physicians' incomes are based on items of service delivered (consultations and interventions) and often include direct out-of-pocket payment by the patient. This forms a barrier to transforming care because it stimulates disease oriented interventions and hampers access-in particular, for poor people, who often have the greatest health needs. To realise equity it is important to provide universal health coverage. However, in India and Bangladesh, particularly, there is resistance to this concept in society.

\section{Multidisciplinary approach}

A multidisciplinary approach is needed to meet the broad range of health problems (from physical to mental and social) in the community and the scope of responses that have to be provided (from support, advice, and health education to preventive, diagnostic, and therapeutic interventions). Sri Lanka, Singapore, and Shanghai-China have all established multidisciplinary teams to provide primary healthcare but other countries are relying on single handed practices, which impede a broad response to the health needs in the community, including to social determinants of health. A related barrier is the cultural-societal value placed on authority, which favours specialists over generalists. ${ }^{21} 22$ This stands in the way of a bottom-up process.

The needs of the large numbers of poor people are especially important when considering how to strengthen primary healthcare. Connecting it to universal health coverage is therefore attractive. ${ }^{123}$ The rationale is that the countries that do not have strong primary healthcare at the heart of their health systems are unable to capitalise on the equitable and cost effective care that it provides. $^{24}$

\section{Future development}

Development of primary healthcare is on the political agenda of all countries that we examined, but they vary in their success in implementing the policy. There is therefore scope for regional collaboration and exchange of experiences. Although our analysis is based on only 11 countries of the region, it provides good information on their policies. From this perspective we make the following recommendations for regional collaboration and action.

- Health policy should aim to move healthcare out of the hospital and into the community and to shift care from disease centred to person or population centred care. To guarantee equity, access to healthcare for all—universal health coverage 1 - and reduction of out-of-pocket payment should form an integral part of this policy.

- Provision of primary healthcare should be restricted to professionals who have been trained in specific primary care competencies and skills. This will require reform of medical schools to support primary healthcare in the medical curriculum, specialty training, and research.

- Professional primary healthcare leadership is required to push for the development of primary healthcare and guide its implementation at community level. Regional and international collaboration can support the building of leadership capacity to overcome primary care's subordinate position to hospital specialists. Models of success in other countries will show policy makers, educators, specialists, community leaders, patients, and other stakeholders the potential of primary care leadership and serve as a beacon for professionals to identify with. It is important to reflect the multidisciplinary nature of primary healthcare by including nurses, midwifes, and allied health professionals.

- Leadership capacity building should be closely linked to medical schools and the healthcare education setting to make sure that primary healthcare professionals can be trained in the community under local health (care) conditions. This is as much a challenge as an opportunity to address the urban-rural divide, so prevalent in many Asian countries, by giving rural communities currently deprived of healthcare a central position in the training of health professionals and build links to universities and medical schools. This collaboration can also support primary healthcare professionals in mastering the research skills to collect data on the population under their care to create a "community diagnosis" - an understanding of the most important health problems and (social) determinants of health that warrant priority action in that community.

- Participation of patients and communities as stakeholders at the local level is an important factor in establishing community needs, but in general there is no tradition in Asia of patient or community participation. Development of strategies to give patients and communities a voice must therefore be included at the start of the reform process.

International collaboration has an important role in health reform, through advocacy of policy development and support on the ground. Such collaboration is well developed in South East Asia with the WHO regional office having a clear strategy to pursue universal health coverage through primary healthcare ${ }^{1}$ and the participation of more and more countries in WONCA. The platforms WHO and WONCA provide for regional collaboration can therefore help implement primary healthcare policy.

Contributors and sources: Both authors have a long experience in developing primary healthcare through international comparisons and exchanges. CvW has been president of WONCA and published widely on primary healthcare research, RK has promoted primary healthcare in Japan to direct health reforms, through the presentation of best practices from around the world. Both authors prepared the two WONCA 


\section{Summary points}

Most countries in Asia are struggling to implement primary healthcare

Primary healthcare receives low investment and education compared with hospital based specialties

Joint action between policy makers, professionals, educators, community leaders, and service users is required to draw health facilities to local communities, train professionals in the local setting, and retain them in community services

Regional and international collaboration can provide models of success and advocacy for the role and function of primary healthcare

workshops and analysed and reported their findings, that formed the basis of this article. CvW developed the outline of the paper and wrote the first draft and final version. RK commented on the outline of the paper and contributed to the first draft in developing its final form. Competing interests: We have read and understood BMJ policy on declaration of interests and have no relevant interests to declare. Provenance and peer review: Not commissioned; externally peer reviewed.

1 WHO South East Asia Region. Resolution on strengthening community based health care service delivery. SEA/RC68/2015. 2015.

2 World Bank. Live long and prosper: aging in East Asia and Pacific. 2016. https:// openknowledge.worldbank.org/handle/10986/23133

3 Starfield B. Is primary care essential? Lancet 1994;356:1129-33. doi:10.1016/S0140-6736( 94)90634-3 pmid:7934497.

4 Macinko J, Starfield B, Shi L. The contribution of primary care systems to health outcomes within Organization for Economic Cooperation and Development (OECD) countries, 1970-1998. Health Serv Res 2003;356:831-65. doi:10.1111/1475-6773.00149 pmid: 12822915.

5 Starfield B, Shi L, Macinko J. Contribution of primary care to health systems and health. Milbank Q 2005;356:457-502. doi:10.1111/j.1468-0009.2005.00409.x pmid:16202000.

6 Hansen J, Groenewegen PP, Boerma WG, Kringos DS. Living in a country with a strong primary care system is beneficial to people with chronic conditions. Health Aff (Millwood) 2015;356:1531-7. doi:10.1377/hlthaff.2015.0582 pmid:26355055.

7 Turner G, Clegg A. British Geriatrics Society Age UK Royal College of General Practioners. Best practice guidelines for the management of frailty: a British Geriatrics Society, Age UK and Royal College of General Practitioners report. Age Ageing 2014;356:744-7. doi: 10.1093/ageing/afu138 pmid:25336440.

8 Frank C, Wilson CR. Models of primary care for frail patients. Can Fam Physician 2015;356:601-6.pmid:26380850.

9 Eklund K, Wilhelmson K, Gustafsson H, Landahl S, Dahlin-Ivanoff S. One-year outcome of frailty indicators and activities of daily living following the randomised controlled trial: "Continuum of care for frail older people". BMC Geriatr 2013;356:76. doi:10.1186/14712318-13-76 pmid:23875866.

10 World Health Organization. The world health report 2008-primary health care, now more than ever. 2008. http://www.who.int/whr/2008/en/
11 World Health Assembly. 2009. Resolution 62.12 Primary health care, including health system strengthening. http://apps.who.int/gb/ebwha/pdf_files/WHA62-REC1/WHA62_ REC1-en.pdf

12 Reeve J, Blakeman T, Freeman GK, et al. Generalist solutions to complex problems: generating practice-based evidence- the example of managing multi-morbidity. BMC Fam Pract 2013:356:112. doi:10.1186/1471-2296-14-112 pmid:23919296.

13 WONCA Europe. The European definition of general practice/family medicine. http://www. woncaeurope.org/sites/default/files/documents/Definition\%203rd\%20ed\%202011\%20with\% 20revised\%20wonca\%20tree.pdf

14 Kidd M, ed. The contribution of family medicine to improving health systems. A guidebook from the World Organization of Family Doctors. 2nd ed. Radcliffe Publishing, 2013.

15 J Am Board Fam Med 2012;356(suppl 1). http://www.jabfm.org/content/25/Suppl_1.toc

16 Kringos D. The strength of primary care in Europe. Thesis, University of Utrecht, 2012. http://www.nivel.nl/sites/default/files/bestanden/Proefschrift-Dionne-Kringos-The-strengthof-primary-care.pdf

17 van Weel C, Turnbull D, Whitehead E, et al. International collaboration in innovating health systems. Ann Fam Med 2015;356:86-7. doi:10.1370/afm.1751 pmid:25583898.

18 WONCA Research Working Party. Multi-national plenary panel project. http://www. globalfamilydoctor.com/groups/WorkingParties/Research/ plenarypanelprojectresourcedocuments.aspx

19 van Weel C, Kassai R, Tsoi GWW, et al. Evolving health policy for primary care in the Asia Pacific region. Br J Gen Pract 2016;356:e451-3. doi:10.3399/bjgp16X685513 pmid: 27231305.

20 van Weel C, Kassai R, Qidwai W, et al. Primary health care policy implementation in South Asia. BMJ Global Health 2016:356:e000057. doi:10.1136/bmigh-2016-000057.

21 Javanparast S, Coveney J, Saikia U. Exploring health stakeholders' perceptions on moving towards comprehensive primary health care to address childhood malnutrition in Iran: a qualitative study. BMC Health Serv Res 2009;356:36. doi:10.1186/1472-6963-9-36 pmid: 19236720.

22 Kassai R. Primary care and the integrated community care system in Japan: roles and future tasks [in Japanese]. Jpn J Health Economic Policy 2014;26:3-26.

23 Jha A, Godlee F, Abbasi K. Delivering on the promise of universal health coverage. BMJ 2016;356:i2216. doi:10.1136/bmj.i2216 pmid:27117561.

24 Stigler FL, Macinko J, Pettigrew LM, Kumar R, van Weel C. No universal health coverage without primary health care. Lancet 2016;356:1811. doi:10.1016/S0140-6736(16)303154 pmid:27203497.

Published by the BMJ Publishing Group Limited. For permission to use (where not already granted under a licence) please go to http://group.bmj.com/group/rights-licensing/ permissions 